\title{
A controlled Intervention Study: Comparison of Intervention on the Antibiotic Prophylaxis of Three Clean Surgeries in Chinese Tertiary Hospitals
}

\author{
Yingdong Zheng ${ }^{1}$, Ying Zhou ${ }^{2}$, Ning Chen ${ }^{3}$, Liang Zhou ${ }^{4}$, Qing Yan $^{5 *}$ \\ ${ }^{1}$ Department of Epidemiology and Biostatistics, School of Public Health, Peking University, Beijing, China; ${ }^{2}$ Department of Phar- \\ macy, Peking University First Hospital, Beijing, China; ${ }^{3}$ Department. of Pharmacy, Jishuitan Hospital, Beijing, China; ${ }^{4}$ Department \\ of Pharmacy, Chinese PLA Hospital 304, Beijing, China; ${ }^{5}$ Department of Pharmacy Management, National Institute of Hospital Ad- \\ ministration, Beijing, China. \\ Email: *yanqing456@126.com
}

Received June 20 ${ }^{\text {th }}$, 2013; revised July 25 ${ }^{\text {th }}, 2013$; accepted August $6^{\text {th }}, 2013$

Copyright (C 2013 Yingdong Zheng et al. This is an open access article distributed under the Creative Commons Attribution License, which permits unrestricted use, distribution, and reproduction in any medium, provided the original work is properly cited.

\begin{abstract}
A controlled intervention study was to promote rational antibiotic prophylaxis in clean surgeries in Chinese tertiary hospitals from 2008 to 2009. The effect of the intervention was measured and compared before and after intervention (intervention group, IG, including twelve hospitals), and compared with the control group (CG, including 164 tertiary hospitals distributed in 31 provinces). There were a total of 3961 and 657 cases identified in IG \& CG for the study. Comparing the changes of IG with CG following the $3^{\text {rd }}$ intervention, the proportion of antibiotics use without indication decreased from $61.9 \%$ (IG) \& 84.4\% (CG) $\chi^{2}$ test, $\mathrm{P}<0.01$ ) to $60.9 \%$ (IG) \& 59.1\% (CG) $\left(\chi^{2}\right.$ test, $\mathrm{P}>0.05$ ); the rationality scores increased from 55.4 (IG) \& 57.6 (CG) (t test, P > 0.05) to 77.0 (IG) \& 64.3 (CG) (t test, P < 0.01) respectively. The results showed that the main problems of irrational antibiotic prophylaxis included antibiotic selection, medication given at wrong time, and the long duration of medication, accounting for $28.1 \%, 34 \%$ and $69.6 \%$ of the total indicated cases respectively. Significant improvements in using antibiotics with indication would help enhance rational use of the antibiotics. There were complicated factors affecting the antibiotics use decision making beyond the capacity of technical interventions.
\end{abstract}

Keywords: Rational Antibiotic Use; Antibiotic Prophylaxis; Clean Surgeries; Thyroidectomy; Mastectomy; Hernia

\section{Introduction}

The use of antibiotic prophylaxis is an accepted and widely practiced feature in modern surgeries. The prevention and control of infection is a priority in healthcare, and the emergence of antibiotic resistance is a worldwide phenomenon. Though a lowered incidence of SSI with the use of prophylactic antibiotics is well documented, the inappropriateness of antibiotic prophylaxis has also been extensively demonstrated in many situations. Antibiotics are often used in wrong doses, for too long, or with too broad a spectrum of antimicrobial activity [1-4]. Antimicrobial resistance, superinfection and unnecessary costs are common consequences of inappropriate surgical antibiotic prophylaxis [2,5]. Hence, rational use of antibiotics is essential.

World Health Assembly (WHA) resolutions in 1998,

"Corresponding author.
2005 and 2007 urged WHO Member States to formulate measures to encourage appropriate and cost-effective use of medicines [6]. Countries were also encouraged to develop sustainable systems to monitor the volumes and patterns of medicine use and the impact of control measures, and to develop and implement effective interventions to improve the use of medicines. The Chinese Ministry of Health committed to work with WHO on this aspect of medicines use. A series of regulations and rules, working mechanisms and approaches have been developed and implemented in health facilities to improve the use of medicines, especially antibiotics. To monitor the volume and patterns of antibiotic use and the impact of control measures, a National Monitoring Network on Clinical Antibiotics Use (Network) was established in China in 2005, and has been regularly collecting antibiotic use data from 120 tertiary general hospitals around the country. The monitoring report from 2006 to 2007 
showed that the proportion of irrational antibiotic use in surgical practice was widespread and serious [7].

With the support of WHO, the Ministry of Health initiated an intervention project to promote rational antibiotic prophylaxis in clean surgeries from 2008 to 2009.

\section{Patients and Methods}

\subsection{Hospital Sampling}

The study was conducted in 176 tertiary hospitals in China totally. The sampling frame is within the Network which consists of 164 tertiary hospitals distributed in 31 provinces as control group (CG). All provinces were divided into three groups based on its annual Gross Domestic Product per capita in 2007, three hospitals were randomly selected from each group, and nine hospitals were selected as intervention group (IG). Three hospitals volunteered to join IG, a total of twelve tertiary general hospitals were included in IG.

\subsection{Target Surgeries}

Three common clean surgeries (thyroidectomy, mastectomy and hernia) were targeted for the intervention.

\subsection{Baseline Survey and Evaluation of Rationality}

Hospitals in IG were required to collect all the medical records of patients who underwent one of the three targeted surgeries, and discharged in the month of March 2008. Two trained clinical pharmacists were responsible for evaluating the rationality of antibiotic prophylaxis of these cases based on the National Guideline [8]. If no antibiotic was used in a case, it was judged as rational. Non-indicated cases treated with antibiotics were judged as irrational. For those indicated cases using antibiotics, a rational use measurement system (Table 1) was formulated by a group of senior clinical specialists. Ten indicators were identified for evaluating the rationality.

Table 1. Indicators and weights of the rationality evaluation system for antibiotic prophylaxis in clean surgeries.

\begin{tabular}{cccc}
\hline Items & Weights & Items & Weights \\
\hline Antibiotics selection & 0.25 & Combination & 0.08 \\
$\begin{array}{c}\text { Single dose of } \\
\text { antibiotics } \\
\text { Daily frequency of } \\
\text { medication }\end{array}$ & 0.11 & $\begin{array}{c}\text { Premedication before } \\
\text { surgical procedure }\end{array}$ & 0.14 \\
$\begin{array}{c}\text { Solvent selection and } \\
\text { dose }\end{array}$ & 0.05 & $\begin{array}{c}\text { Medication in surgical } \\
\text { procedure }\end{array}$ & 0.07 \\
$\begin{array}{c}\text { Routes of administration } \\
\text { Postoperative medication }\end{array}$ & 0.05 & Change antibiotics & 0.12 \\
\hline
\end{tabular}

Each indicator was given a weight, important factors received higher scores. The value range of the rationality score ranged 1 - 100, the larger the score, the more rational the antibiotic use was.

\subsection{Interventions}

A set of intervention strategies was implemented in the twelve hospitals in IG in three waves between May 2008 and May 2009 (May. to Sep. 2008, Jan. to Feb. 2009, and Apr. to May 2009 respectively), which covered administrative and technical interventions implemented by both the central authority and the local hospitals. Central authority administrative interventions consisted of circulation and implementation of the regulation of Enhance management of rational application of antimicrobials in clinic, issued by the Ministry of Health [9], and also the Ministry of Health's views about management of application of antimicrobials in clinics [10]. Central authority technical interventions comprised launching the Drug and Therapeutics Committee (DTC) training course in the respective provinces, and circulating to physicians with materials and literatures on rational antibiotic prophylaxis in clean surgery. Hospital administrative interventions included formulating the rules of Antimicrobials' application in hospital, and compiling the Management catalogue of antimicrobials in hospitals. Hospital technical interventions involved establishing focused groups and using the Monitoring/Training/Planning (MTP) method [11] to assist the compliance of relevant rules and regulations, identifying and setting targets and strategies for those outliers of antibiotic prophylaxis in the three targeted clean surgeries.

\subsection{Post intervention Data Collection and Analysis}

Post intervention data collection and evaluation of rationality were conducted after each intervention in the month of Sep. 2008, Mar. and Jun. 2009 in IG. The scope and objective of the data collection were the same as that of the baseline survey. Rationality scores were calculated statistically based on the weight of each of the ten indicators, in order to evaluate the effect of the intervention. The general linear model (GLM) statistical tool was applied for multiple factor analysis on numerical data. GLM of Repeated Measure was used to trend test rationality scores pre- and post-intervention.

\subsection{External Control}

To avoid the time selection confounding factor due to the self-controlled design, this study took the Network as the external control group (CG), and conducted multi-factor analysis using the GLM. According to the routine data 
reporting procedures of the Network, each hospital was required to randomly select fifteen surgery cases from all the discharged cases in the $2^{\text {nd }}$ week of the $1^{\text {st }}$ month of each quarter (Jan. Mar., June and Sept.), and reported to the Network every half year in June and Dec. There were 164 hospitals providing data to the Network in Mar.2008, and 171 hospitals in Mar. and June 2009 (additional hospitals joint the Network). All targeted clean surgery cases were identified from the Network as control sample. The database was built with Epidata ${ }^{\circledR} 3.1$ and all data analysis was done by SPSS ${ }^{\circledR} 11.0$.

The Ministry of Health approved and supported this study, and allowed use of data collected from IG and the Network. All hospitals were informed of the study.

\section{Results}

\subsection{Number of Cases}

There were a total of 3,961 cases enrolled in the IG in the whole course of all interventions, and 657 cases analyzed in the CG. Considering the workload of extracting CG data from the Network half year reporting system, only cases in Mar. 2008 were separated from the reporting system as baseline sample (212), while the cases reported in the first half year of 2009 were not separated, which included the cases collected in Mar. and Jun. (445). Table 2 shows the number and percentage of cases specified by both time and type of surgeries.

\subsection{Duration of Medication and Combination}

The average duration of antibiotic medication declined from 4.9 to 4.1 days after three waves of interventions ( $P$ $<0.05$, Kruskal-Wallis, H. test), the incidence of pre0 scribing a combination of antibiotics also declined slightly (Table 3).

Table 2. Number and percentage of cases enrolled in the project during four study periods.

\begin{tabular}{cccccc}
\hline \multirow{4}{*}{ Study period } & \multicolumn{4}{c}{ IG } & CG \\
\cline { 2 - 6 } & $\begin{array}{c}\text { Thyroidectom } \\
\text { y cases (\%) }\end{array}$ & $\begin{array}{c}\text { Mastectomy } \\
\text { cases (\%) }\end{array}$ & $\begin{array}{c}\text { Hernia } \\
\text { cases (\%) }\end{array}$ & $\begin{array}{c}\text { Total } \\
\text { cases }\end{array}$ & $\begin{array}{c}\text { Total } \\
\text { cases }\end{array}$ \\
\hline $\begin{array}{c}\text { baseline } \\
1^{\text {st }}\end{array}$ & $382(39.8)$ & $324(33.8)$ & $253(26.4)$ & 959 & 212 \\
$\begin{array}{c}\text { intervention } \\
2^{\text {nd }}\end{array}$ \\
$\begin{array}{c}\text { intervention } \\
3^{\text {rd }}\end{array}$ & $417(38.9)$ & $320(39.3)$ & $178(21.8)$ & 815 & $/$ \\
$\begin{array}{c}\text { intervention } \\
\text { Total }\end{array}$ & $469(49.5)$ & $435(40.6)$ & $213(19.9)$ & 1071 & \\
\hline
\end{tabular}

IG, intervention group. CG, control group. "Percentage of the number of deferent clean surgeries in the number of IG.

\subsection{Rationality Evaluation on Antibiotic Use}

Table 4 shows the composition of three categories of cases (Pearson $\chi^{2}$ test, $\mathrm{P}<0.01$ ). The percentage of cases not using antibiotics (rational) after the first intervention increased significantly from $3.5 \%$ to $11.5 \%$, and remained at that level following the second (12.3\%) and third interventions (11.9\%). As these were elective clean cases, these were very low figures. The percentage of non-indicated cases treated with antibiotics (irrational) was reduced from $61.9 \%$ to $53.1 \%$ after two waves of interventions, but rebounded to $60.9 \%$ in June 2009 following the $3^{\text {rd }}$ wave of intervention.

Table 5 shows the rationality scores of the indicated

Table 3. Duration of medication and combination of antibiotics during four study periods.

\begin{tabular}{ccccc}
\hline & $\begin{array}{c}\text { Duration of } \\
\text { medication } \\
\text { (days) }\end{array}$ Study period & \multicolumn{3}{c}{$\begin{array}{c}\text { The number and incidence of } \\
\text { prescribing combination of antibiotics }\end{array}$} \\
\cline { 3 - 6 } & $\begin{array}{c}\text { Mean } \pm \text { SD } \\
\text { (No. of cases) }\end{array}$ & $\begin{array}{c}\text { Using only } \\
\text { antibiotic }\end{array}$ & $\begin{array}{c}\text { combination } \\
\text { two kinds of } \\
\text { antibiotic }\end{array}$ & $\begin{array}{c}\text { Prescribing } \\
\text { combination } \\
\text { antibiotic }\end{array}$ \\
\hline baseline & $\begin{array}{c}4.9 \pm 3.3 \\
(922)\end{array}$ & $724(75.5)$ & $162(16.9)$ & $39(4.1)$ \\
$1^{\text {st }}$ intervention & $\begin{array}{c}4.3 \pm 3.5 \\
(721)\end{array}$ & $549(67.4)$ & $127(15.6)$ & $45(5.5)$ \\
$2^{\text {nd }}$ intervention & $\begin{array}{c}4.1 \pm 2.6 \\
(939)\end{array}$ & $782(73.0)$ & $134(12.5)$ & $23(2.1)$ \\
$3^{\text {rd }}$ intervention & $\begin{array}{c}4.1 \pm 2.9 \\
(983)\end{array}$ & $766(68.6)$ & $181(16.2)$ & $36(3.2)$ \\
\hline
\end{tabular}

Table 4. Composition of cases not using antibiotics and using antibiotics with and without indications during four study periods ( No. (\%) of cases).

\begin{tabular}{ccccc}
\hline Study period & $\begin{array}{c}\text { not using } \\
\text { antibiotic }\end{array}$ & $\begin{array}{c}\text { using antibiotic } \\
\text { without } \\
\text { indications }\end{array}$ & $\begin{array}{c}\text { using antibiotic } \\
\text { with } \\
\text { indications }\end{array}$ & Total \\
\hline baseline & $34(3.5)$ & $594(61.9)$ & $331(34.5)$ & $959(100)$ \\
$1^{\text {st }}$ intervention & $94(11.5)$ & $486(59.6)$ & $235(28.8)$ & $815(100)$ \\
$2^{\text {nd }}$ intervention $132(12.3)$ & $569(53.1)$ & $370(34.5)$ & $1071(100)$ \\
$3^{\text {rd }}$ intervention 133 (11.9) & $680(60.9)$ & $303(27.2)$ & $1116(100)$ \\
\hline
\end{tabular}

Table 5. Rationality scores of the indicated cases (mean \pm SD (N)) during four study periods.

\begin{tabular}{ccccc}
\hline Study period & Thyroidectomy Mastectomy Hernia repair & total \\
\hline baseline & $57.9 \pm 25.2$ & $53.2 \pm 21.7$ & $56.1 \pm 20.7$ & $55.4 \pm 21.6$ \\
& $(43)$ & $(113)$ & $(175)$ & $(331)$ \\
$1^{\text {st }}$ & $68.7 \pm 17.3$ & $74.2 \pm 15.9$ & $68.4 \pm 17.1$ & $71.1 \pm 16.8$ \\
intervention & $(56)$ & $(106)$ & $(73)$ & $(235)$ \\
$2^{\text {nd }}$ & $69.6 \pm 19.4$ & $73.0 \pm 21.0$ & $74.7 \pm 17.2$ & $73.0 \pm 19.6$ \\
intervention & $(60)$ & $(179)$ & $(125)$ & $(364)$ \\
$3^{\text {rd }}$ & $75.4 \pm 17.1$ & $79.7 \pm 17.1$ & $75.0 \pm 14.5$ & $77.0 \pm 16.4$ \\
intervention & $(77)$ & $(121)$ & $(105)$ & $(303)$ \\
\hline
\end{tabular}


cases treated with antibiotics before and after each intervention. Calculating the average rationality score of the 12 hospitals in IG, through conducting the GLM analysis, we found that the rationality score of IG significantly increased from 55.4 to 71.1 after the first round of intervention $(P<0.05)$, while improvements of the second and third waves of interventions were not obvious, it increased to 77 following the $3^{\text {rd }}$ wave of intervention.

\subsection{Key Problems of the Indicated Cases Following Interventions}

The key irrational antibiotic prophylaxis problems existed following three waves of interventions are: wrong antibiotic selection, medication given at the wrong time, and the long duration of medication, which occurred in $28.1 \%, 34 \%$ and $69.6 \%$ of the total indicated cases respectively as showed in Table 6.

\subsection{Comparison of IG versus CG}

\subsubsection{Baseline}

The percentage of cases using antibiotics without indications in IG and CG was $61.9 \%$ and $84.4 \%$ respectively, IG was significantly lower than CG $\left(\chi^{2}\right.$ test, $\left.\mathrm{P}<0.01\right)$. There was no significant difference of the rational scores on the cases using antibiotics with indications between IG (55.4) and CG (57.6) (t test, P > 0.05).

\subsubsection{Post Interventions}

The proportion of patients who were prescribed antibiotics without indications in IG decreased from $61.9 \%$ to $59.1 \%$, which experienced reductions following the $1^{\text {st }}$ and $2^{\text {nd }}$ interventions, and rebound following the $3^{\text {rd }}$ intervention. The decreasing range between baseline and post $3^{\text {rd }}$ intervention was not as much as in CG, which was from $84.4 \%$ to $60.9 \%$. The difference between the proportions in IG and CG after the $3^{\text {rd }}$ intervention was not significant $\left(\chi^{2}\right.$ test, $\left.\mathrm{P}>0.05\right)$ (Figure 1). The rationality scores of the cases using antibiotics with indications in IG increased from 55.4 to 77.0 following the 3rd intervention, and that in CG also increased from

Table 6. Proportion of indicated cases with major irrational antibiotic prophylaxis problems during four study periods.

\begin{tabular}{cccc}
\hline \multirow{2}{*}{$\begin{array}{c}\text { Study period } \\
\text { respective problem/total number of indicated cases) }\end{array}$} \\
\cline { 2 - 4 } & $\begin{array}{c}\text { Wrong antibiotic } \\
\text { selection }\end{array}$ & $\begin{array}{c}\text { Medication given } \\
\text { at the wrong time }\end{array}$ & $\begin{array}{c}\text { Long duration } \\
\text { of medication }\end{array}$ \\
\hline baseline & $51.7(171 / 331)$ & $68.0(225 / 331)$ & $86.4(286 / 331)$ \\
$1^{\text {st }}$ intervention & $37.0(87 / 235)$ & $38.3(90 / 235)$ & $76.2(179 / 235)$ \\
$2^{\text {nd }}$ intervention & $35.4(129 / 364)$ & $34.6(126 / 364)$ & $81.0(295 / 364)$ \\
$3^{\text {rd }}$ intervention & $28.1(85 / 303)$ & $34.0(103 / 303)$ & $69.6(211 / 303)$ \\
\hline
\end{tabular}

57.6 to 64.3 , the rationality scores of IG was significantly higher than that in CG following the 3rd intervention ( $\mathrm{t}$ test, $\mathrm{P}<0.01$ ) (Figure 2).

Conducting multi-factor analysis with GLM, we found there was an interaction between the grouping variables in terms of hospitals (IG and CG) and times (before and after interventions) (Figure 2).

\section{Discussion and Conclusion}

\subsection{Discussion}

After three waves of interventions, the antibiotic prophylaxis of three targeted clean surgeries in IG was improved overall, although a small proportion of patients did not receive antibiotics. There was limited effect on changing the behaviour of using antibiotics for nonindicated cases. Further efforts needed to be made to solve the remaining problems, principally for the follo wing reasons.

\subsubsection{Absence of Consistent Operational Regulations and Guidelines}

Although the Ministry of Health issued a series of regulations, such as the National Guidelines [8], the Guide-

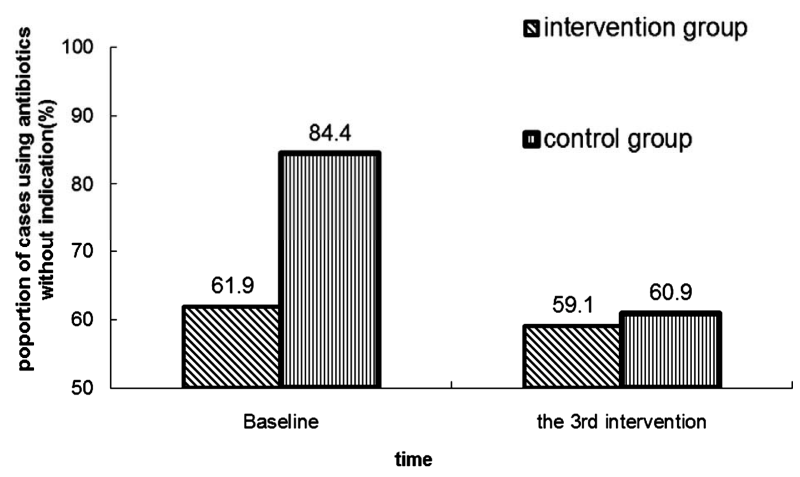

Figure 1. Proportion of cases using antibiotics without indication.

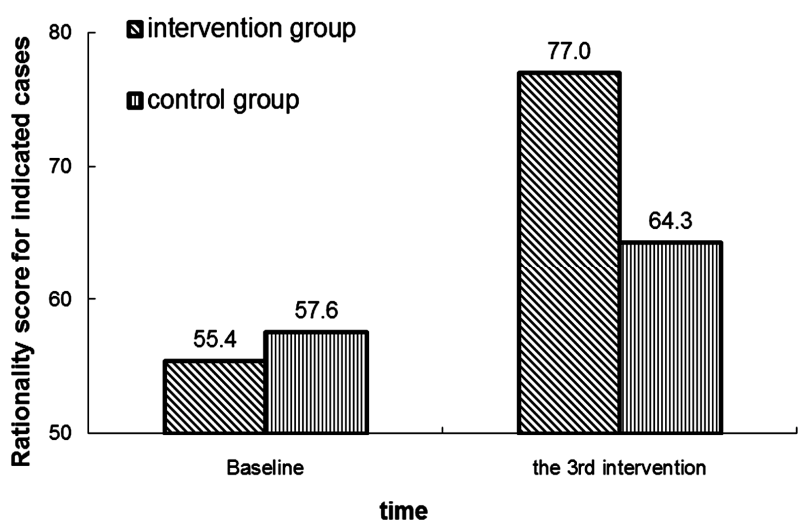

Figure 2. Rationality score for indicated cases treated with antibiotics. 
line on Infection Control with Antibiotics in Surgeries [12], the Notice of Further Strengthening the Regulation on Antibiotics Clinical Use [9], putting them into practice has been problematic. For example, the dose recommended in the Clinical Pathway for Nodular Goiter (2009) [13] is not applicable to cases that may develop into cancer but in most instances it is very difficult to evaluate such a risk before surgery takes place.

\subsubsection{Authoritativeness of Different Guidelines}

There is no well organized expert consultation process, and no standardized evidence based mechanism for guideline development. For example, in terms of medication time for antibiotic prophylaxis, the National Guidelines require that antibiotics should not be permitted for 24 hours following surgery in non-exceptional circumstances. However, the Clinical Pathway for Breast Cancer guidelines (2009) dose not allow antibiotics for 72 hours following surgeries [14]. Doctors do not know which guidelines to follow.

\subsubsection{Intervention Intensity}

Promoting rational use of medicines needs continued effort, one-time administrative intervention will inevitably be unsustainable. Hospitals in IG followed the same technical approaches, but with a different variety and intensity of administrative measures. Effective technical interventions always require relevant administrative interventions, to maintain the sustainability of the intervention effect.

\subsubsection{Limitations of Technical Interventions for Health System Problems}

Technical interventions have a limited effect on convincing doctors not to use antibiotics for cases for which they are not indicated, as comprehensive problems exist that go beyond the knowledge and prescribing habits of doctors. Perverse incentives that exist in the health system have driven doctors to use antibiotics even for those cases for which they are not indicated [6]. Placing the responsibility of proof on doctors in medical disputes about unexpected infections due to failure to control hygiene risks in operating theatres may also be a factor in risk avoidance by over prescribing.

All hospitals in IG were in the Network, In addition to this, the three additional volunteered hospitals also brought selective bias to the project. Constrained by the CG data from the available Network database, and the data collection workload, the sampling methods for the cases in IG and CG are different, so there is a large gap of numbers of cases included in the data analysis between IG and CG, and the CG data did not excluded the data contributed to the Network data base by the twelve hospitals in IG, all these made the control is not a perfect external control. This project targeted frequently performed simple clean surgeries. More common surgeries could be included and the project expanded to outpatients in the future. Electronic prescription and advanced health information systems could also enable more advanced evaluation methods for future studies.

\subsection{Conclusions}

- The baseline investigation indicates that in China the problem of irrational antibiotic prophylaxis for clean surgeries was very serious, with $80 \%-90 \%$ of cases irrationally treated with antibiotics.

- The intervention was effective overall, with statistically significant improvements following the interventions, but $50 \%-60 \%$ of the cases were still treated irrationally. The key problem is using antibiotics without indication.

- Among the cases with indications, the main problems of irrational antibiotic prophylaxis were antibiotic selection, medication given at the wrong time and the long duration of medication.

- There was a statistically significant improvement in performance after the first intervention, the improvements that followed the second and the third interventions were slight, with some indicators getting worse, which indicated the difficulty of changing established "wrong" practices. More comprehensive approaches and continued efforts would be needed.

There was a significant improvement in cases treated with antibiotics with indication after the interventions, but very little improvement in the cases without indication. This indicated that there may be other factors that affect the doctors' decision not to use antibiotics, such as health system problems and patients' expectations.

\section{REFERENCES}

[1] J. S. Currier, H. Campbell, R. Platt and A. B. Kaiser, "Perioperative Antimicrobial Prophylaxis in Middle Tennessee,” Reviews Infectious Diseases, Vol. 13, No. 10, 1991, pp. S874-S878. doi:10.1093/clinids/13.Supplement_10.S874

[2] P. Gorecki, M. Schein, J. C. Rucinski and L. Wise, "Antibiotic Administration in Patients Undergoing Common Surgical Procedures in a Community Teaching Hospital: The Chaos Continues,” World Journal Surgery, Vol. 23, No. 5, 1999, pp. 429-432. doi:10.1007/PL00012319

[3] R. G. Holzeheimer, W. Haupt, A. Thiede and A. Schwarzkopf, "The Challenge of Postoperative Infections: Does the Surgeon Make a Difference?” Infection Control and Hospital Epidemiology, Vol. 18, No. 6, 1997, pp. 449-456. doi:10.1086/647646

[4] E. Mini, S. Nobili and P. Periti, "Methicillin-Resistant 
Staphylococci in Clean Surgery Is There a Role for Prophylaxis?” Drugs, Vol. 54, No. 6, 1997, pp. S39-S52. doi:10.2165/00003495-199700546-00008

[5] J. E. Mcgowan Jr., "Cost and Benefit of Perioperative Antimicrobial Prophylaxis: Methods for Economic Analysis,” Reviews Infectious Diseases, Vol. 13, No. 10, 1991, pp. S879-S889.

[6] World Health Assembly Resolutions: 51.17, Emerging and Other Communicable Diseases: Antimicrobial Resistance; 58.27, Improving the Containment of Antimicrobial Resistance; 60.16, Progress in the Rational Use of Medicines, Including Better Medicines for Children.

[7] Ministry of Health, "Report of the National Monitoring Network on Clinical Antibiotics Use,” Beijing, 2008.

[8] The Institute of Hospital Management, Ministry of Health, "Guideline on Clinical Antibiotics Use," Department of Drug Management Research, Beijing, 2007.

[9] Ministry of Health, "Enhanced Management of Rational Application of Antimicrobials in Clinics,” Beijing, 2008.
[10] Ministry of Health, "Views about Management of Application of Antimicrobials in Clinics,” Beijing, 2009.

[11] S. Suryawati and B. Santoso, "MTP Approach Is Effective in Reducing Inappropriate Medicines Use in Hospitals," Presentation at the 2nd International Conference on Improving Use of Medicines, Chiang Mai, 30 March 2004.

[12] Department of Drug Management Research, Institute of Hospital Management, Ministry of Health, "Guideline on Infection Control with Antibiotics in Surgeries,” Beijing, 2007.

[13] Ministry of Health, “Guidelines on Management by Clinical Pathways,” Beijing, 2009.

[14] W. Chen, S. L. Tang, J. Sun, D. Ross-Degnan and A. Wagner, "How to Perform a Critical Analysis of a Randomized Controlled Trial," BMC Health Services Research. Vol. 10, 2010, p. 211. doi:10.1186/1472-6963-10-211 